\title{
Kinetic and thermodynamic parameters for thermal denaturation of ovine milk lactoferrin determined by its loss of immunoreactivity
}

\author{
F. Navarro, ${ }^{1}$ S. Harouna, M. Calvo, M. D. Pérez, and L. Sánchez ${ }^{2}$ \\ Tecnología de los Alimentos, Facultad de Veterinaria, Universidad de Zaragoza, Miguel Servet 177, 50013 Zaragoza, Spain
}

\begin{abstract}
Lactoferrin is a protein with important biological functions that can be obtained from milk and by-products derived from the dairy industry, such as whey. Although bovine lactoferrin has been extensively studied, ovine lactoferrin is not quite as well known. In the present study, the effect of several heat treatments in 3 different media, over a temperature range from 66 to $75^{\circ} \mathrm{C}$, has been studied on lactoferrin isolated from sheep milk. Denaturation of lactoferrin was determined by measuring its immunoreactivity with specific polyclonal antibodies. Kinetic and thermodynamic parameters obtained indicate that lactoferrin denatures by heat more rapidly in whey than in phosphate buffer or milk. The value of activation energy found for the denaturation process of lactoferrin when treated in whey is higher $(390 \mathrm{~kJ} / \mathrm{mol})$ than that obtained in milk $(194 \mathrm{~kJ} / \mathrm{mol})$ or phosphate buffer $(179 \mathrm{~kJ} / \mathrm{mol})$. This indicates that a great amount of energy is necessary to start denaturation of ovine lactoferrin, probably due to the interaction of this protein with other whey proteins. The changes in the hydrophobicity of lactoferrin after heat treatments were determined by fluorescence measurement using acrylamide. The decrease in the hydrophobicity constant was very small for the treatments from 66 to $75^{\circ} \mathrm{C}$, up to $20 \mathrm{~min}$, which indicates that lactoferrin conformation did not experienced a great change. The results obtained in this study permit the prediction of behavior of ovine lactoferrin under several heat treatments and show that high-temperature, short-time pasteurization $\left(72^{\circ} \mathrm{C}, 15 \mathrm{~s}\right)$ does not cause loss of its immunoreactivity and, consequently, would not affect its conformation and biological activity.
\end{abstract}

Key words: ovine lactoferrin, sheep milk, thermal denaturation, whey

Received January 30, 2015.

Accepted March 27, 2015.

${ }^{1}$ Present address: Facultad de Medicina, Escuela de Nutrición y Dietética, Universidad de Los Andes, Avenida Don Tulio, Mérida 5101, Venezuela.

${ }^{2}$ Corresponding author: lousanchez@unizar.es

\section{INTRODUCTION}

Milk contains many bioactive components, and among them, those with defensive activity are of great importance for the newborn. Lactoferrin, which is present in the milk of the majority of mammalian species, takes part in the nonspecific defensive system of this secretion, together with lysozyme and lactoperoxidase. Lactoferrin is an iron-binding protein that belongs to the non-heme transferrin family, and it has been described as a multifunctional protein, because it can exert several biological functions related to its antibacterial activity, antioxidant properties, antitumoral activity, and participation in iron absorption (Sánchez et al., 1992a). All these properties confer a great value to lactoferrin for its use as supplement in functional products or in nutraceutical products.

The procedure most widely applied to preserve milk and dairy products is heat treatment. However, heat treatment has some adverse effects in milk products because it causes a decrease in the levels of some nutrients and impairs their organoleptic characteristics (Considine et al., 2007). Furthermore, heat treatment induces denaturation and aggregation of milk proteins, thus modifying their biological activity and technological properties (Anema, 2009). The effect of heat treatment on lactoferrin has been studied in several ruminant species, such as bovine (Sánchez et al. 1992b) and caprine (Sreedhara et al., 2010), and also in human lactoferrin from milk and from recombinant origin (Mata et al., 1998; Conesa et al., 2007; Mayayo et al., 2014). Those studies have been performed by using several analytical techniques to evaluate denaturation, such as differential scanning calorimetry (Sánchez et al., 1992b; Mata et al., 1998; Conesa et al., 2007), fluorescence measurement, circular dichroism (Sreedhara et al., 2010), and immunochemical techniques (Sánchez et al., 1992b). However, as far as we know, no systematic studies have been reported on thermoresistance of ovine lactoferrin. Cow milk is normally the source selected for obtaining lactoferrin to be used as ingredient, although other materials such as whey from cheese manufacture can also be used. The production of cheese from sheep milk is very important in the Mediterranean countries 
and, consequently, a large amount of whey is generated in this process. Whey is a valuable by-product due to its protein content of high level and quality, and is also a good source for bioactive proteins, such as lactoferrin or lactoperoxidase. The procedure for cheese manufacture comprises multiple technological variables related to temperature of treatment for milk pasteurization and curd heating before whey draining. Therefore, it is necessary to know the influence of those conditions when the whey is going to be used to isolate bioactive proteins.

The aim of this work has been to study the effect of various heat treatments on the denaturation process of ovine lactoferrin in 3 different media. Thus, the thermoresistance of lactoferrin in sheep milk and whey and also of isolated lactoferrin in phosphate buffer has been determined. Denaturation of lactoferrin has been estimated by measuring its immunoreactivity and determining hydrophobicity that indicates the integrity of the conformational protein structure.

\section{MATERIALS AND METHODS}

\section{Obtaining Lactoferrin from Ovine Milk}

Sheep's raw milk was donated by Villacorona (El Burgo de Ebro, Zaragoza, Spain). Milk was skimmed by centrifugation at $2,000 \times g\left(4^{\circ} \mathrm{C}\right)$ for $15 \mathrm{~min}$. Then, milk was coagulated with rennet from Abiasa (Pontevedra, Spain) in a proportion of $1: 15,000$, maintaining milk in a thermostatic bath at $34^{\circ} \mathrm{C}$ for $40 \mathrm{~min}$. Coagulated caseins were eliminated by centrifugation at 2,000 $\times \mathrm{g}$ $\left(4^{\circ} \mathrm{C}\right)$ during $15 \mathrm{~min}$ and the whey obtained was dialyzed in a membrane with a $10-\mathrm{kDa}$ molecular weight cutoff (MWCO), against $0.015 M$ Tris- $\mathrm{HCl}$ buffer, $\mathrm{pH}$ 6.8. The dialyzed whey was applied to a CM-Sephadex column previously equilibrated with the same buffer, at a flow rate of $0.1 \mathrm{~mL} / \mathrm{min}$, and the fractions collected were of $2 \mathrm{~mL}$. To elute the bound proteins, a first elution step was applied with $0.2 \mathrm{M} \mathrm{NaCl}$ and a second one with $0.5 \mathrm{M} \mathrm{NaCl}$ in the same Tris buffer. The fractions that contained lactoferrin were concentrated in ultrafiltration cones of $10-\mathrm{kDa} \mathrm{MWCO}$, dialyzed and lyophilized. Fractions from chromatography were analyzed by SDS-PAGE.

\section{Obtaining Rabbit Antisera Against Ovine Lactoferrin}

Antisera against ovine lactoferrin were developed in rabbits following procedures under Project License PI48/10 approved by the in-house Ethic Committee for Animal Experiments from the University of Zaragoza. The care and use of animals were performed in accordance with the Spanish Policy for Animal Protection
RD1201/05, which meets the European Union Directive $86 / 609$ on the protection of animals used for experimental and other scientific purposes. A volume of 0.5 $\mathrm{mL}$ of ovine lactoferrin $(2 \mathrm{mg} / \mathrm{mL})$ was homogenized with $0.5 \mathrm{~mL}$ of complete Freund's adjuvant and administered in several subcutaneous injections in the back of the animals. After $3 \mathrm{wk}$, the animals were boosted following the same protocol as in the first immunization, although using incomplete Freund's adjuvant. Ten days later, the animals were cannulated and bled from an ear vein. Double immunodiffusion and immunoelectrophoresis were used to test the antisera, which were shown to be specific for ovine lactoferrin.

\section{Thermal Treatment of Ovine Lactoferrin}

For the study of the effect of heat treatment on lactoferrin denaturation, skim milk and whey were used, in which lactoferrin concentration was of $0.2 \mathrm{mg} / \mathrm{mL}$. The thermoresistance of lactoferrin in $0.05 \mathrm{M}$ monosodium phosphate buffer, $1 M \mathrm{NaCl}, 1 \mathrm{M} \mathrm{KCl}, \mathrm{pH} 7.4$, was determined by dissolving the isolated lactoferrin at 0.2 $\mathrm{mg} / \mathrm{mL}$. Lactoferrin samples were introduced into glass capillaries and subjected to thermal treatments at several temperatures and holding times. A sample of $20 \mu \mathrm{L}$ was introduced per capillary, and both ends were sealed with a microflame. Capillaries were introduced by duplicate in a thermostatic bath with agitation, which maintained the temperature with a precision of $\pm 0.1^{\circ} \mathrm{C}$. After each holding time of treatment, capillaries were removed from the bath and cooled immediately in an ice water bath.

\section{Determination of Ovine Lactoferrin Concentration}

Samples after heat treatment were extracted from the capillaries, and $7 \mu \mathrm{L}$ of every sample was introduced in each well of a $1.5 \%$ agarose gel prepared to develop radial immunodiffusion as described by Sánchez et al. (1992b). The gel was prepared with $0.5 \%$ ( $\mathrm{vol} / \mathrm{vol}$ ) of rabbit antiserum against ovine lactoferrin and the lactoferrin standards prepared at concentrations of 0.3 , $0.2,0.15$, and $0.075 \mathrm{mg} / \mathrm{mL}$.

\section{Decimal Reduction Time and Z Values for the Denaturation of Ovine Lactoferrin}

The effect of thermal treatments on the structure of lactoferrin was evaluated by determining its immunoreactive concentration along time of treatment, for each temperature and treatment medium. To calculate the kinetic parameters for denaturation of lactoferrin, the values of the logarithm of protein concentration were represented against time of treatment. The inverse of 
the slope of the line obtained corresponded with the time required to denature $90 \%$ of the protein; this value is called $\mathrm{D}$ value or decimal reduction time. The graphical representation of the logarithm of $\mathrm{D}$ values versus the temperature gives the $\mathrm{Z}$ value that corresponds with the reciprocal of the slope and represents the number of degrees necessary to reduce the $\mathrm{D}$ value in $1 \log$ cycle.

\section{Order of Reaction and Rate Constants}

The concentration of immunoreactive lactoferrin obtained for each temperature and holding time was analyzed by the equation:

$$
\left(\frac{c_{t}}{c_{o}}\right)^{1-n}=1+(n-1) \cdot k^{\prime} \cdot t,
$$

in which $c_{o}$ is the initial concentration of protein, $c_{t}$ is the concentration at each time of heat treatment $(\mathrm{t})$, and $\mathrm{n}$ is the order of reaction considered to calculate the rate constant for the denaturation process $(\mathrm{k})$ in the 3 different media studied.

\section{Calculation of Thermodynamic Parameters}

The apparent activation energy for the heat denaturation process of lactoferrin was calculated from the values of the rate constants obtained at each temperature and in each medium of treatment by using the Arrhenius equation:

$$
\mathrm{k}=\mathrm{A}^{\frac{\mathrm{E}_{\mathrm{A}}}{\mathrm{R} \times \mathrm{T}}}
$$

in which $\mathrm{k}$ is the rate constant, $\mathrm{A}$ is the Arrhenius constant, $\mathrm{E}_{\mathrm{A}}$ is the apparent activation energy, $\mathrm{R}$ is the universal gas constant, and $\mathrm{T}$ is the absolute temperature. The graphical representation of the natural logarithms of the rate constants $(\mathrm{k})$ against the inverse of the absolute temperature allowed determining the activation energy from the slope of the straight line.

From the value of activation energy and using the equations

$$
\begin{aligned}
& \Delta \mathrm{H} \#=\mathrm{E}_{\mathrm{A}}-\mathrm{R} \times \mathrm{T}, \\
& \Delta \mathrm{S} \#=R \cdot\left[\ln \mathrm{A}-\ln \left(\frac{\mathrm{K}_{\mathrm{B}}}{\mathrm{h}}\right)-\ln \mathrm{T}\right], \text { and } \\
& \Delta \mathrm{G} \#=\Delta \mathrm{H} \#-\mathrm{T} \cdot \Delta \mathrm{S} \#,
\end{aligned}
$$

where $\mathrm{K}_{\mathrm{B}}$ is the Boltzmann constant and $\mathrm{h}$ is the Planck constant, and the following thermodynamic parameters were calculated: variation of the activation enthalpy $(\Delta \mathrm{H} \#)$, variation of the activation entropy $(\Delta \mathrm{S} \#)$, and variation of the free energy of activation $(\Delta \mathrm{G} \#)$.

\section{Determination of Hydrophobicity by Fluorescence Quenching with Acrylamide}

The determination of fluorescence quenching using acrylamide was performed according to Eftink and Ghiron (1981). The fluorescence due to tryptophan was determined using an excitation wavelength of $295 \mathrm{~nm}$ and an emission wavelength of $337 \mathrm{~nm}$. The samples of lactoferrin were prepared at a concentration of $0.1 \mathrm{mg} /$ $\mathrm{mL}$ in $10 \mathrm{~m} M$ sodium phosphate with $\mathrm{pH} 7.2$, treated at different temperatures and holding times, and after cooling them, a volume of $3 \mathrm{~mL}$ was introduced into a cuvette to measure fluorescence. The fluorescence of lactoferrin samples before addition of acrylamide was considered as $\mathrm{F}_{0}$. Aliquots of $12 \mu \mathrm{L}$ of a $5 \mathrm{M}$ acrylamide solution were added to reach a final concentration of $0.2 M$ in the cuvette. The ratio $\mathrm{F}_{0} / \mathrm{F}$ was represented versus the acrylamide concentration $(\mathrm{Q})$ and the slope of the graphs was defined as the apparent constant $\mathrm{K}_{\mathrm{ap}}$, with this value being considered as the relative hydrophobicity:

$$
\frac{\mathrm{F}_{0}}{\mathrm{~F}}=\mathrm{K}_{\mathrm{ap}} \cdot[\mathrm{Q}] .
$$

\section{RESULTS AND DISCUSSION}

In this study, lactoferrin has been isolated from sheep milk by cationic exchange chromatography with good purity and yield. The chromatographic profile and electrophoresis of fractions can be seen in Figure 1. The electrophoretic pattern shows that the band corresponding to the molecular weight of lactoferrin ( 80 $\mathrm{kDa}$ ) appears in the second peak eluted with $0.5 \mathrm{M}$ of sodium chloride, as previously described for bovine lactoferrin (Yoshida and Ye-Xiuyun, 1991). The purity of the isolated lactoferrin was higher than $90 \%$. The band that appears very faint in the lane corresponding to the first peak eluted with $0.2 \mathrm{M}$ of sodium chloride was identified as lactoperoxidase by immunodiffusion with polyclonal antibodies against bovine lactoperoxidase (data not shown). The iron content of the isolated lactoferrin was determined by inductively coupled plasma-mass spectrometry at the Central Analysis Service (University of Zaragoza) and was found to be 0.133 $\mathrm{mg} / \mathrm{mL}$. This amount of iron indicates that $19 \%$ of the protein is saturated.

The effect of heat treatment on lactoferrin was determined by measuring its concentration by an im- 

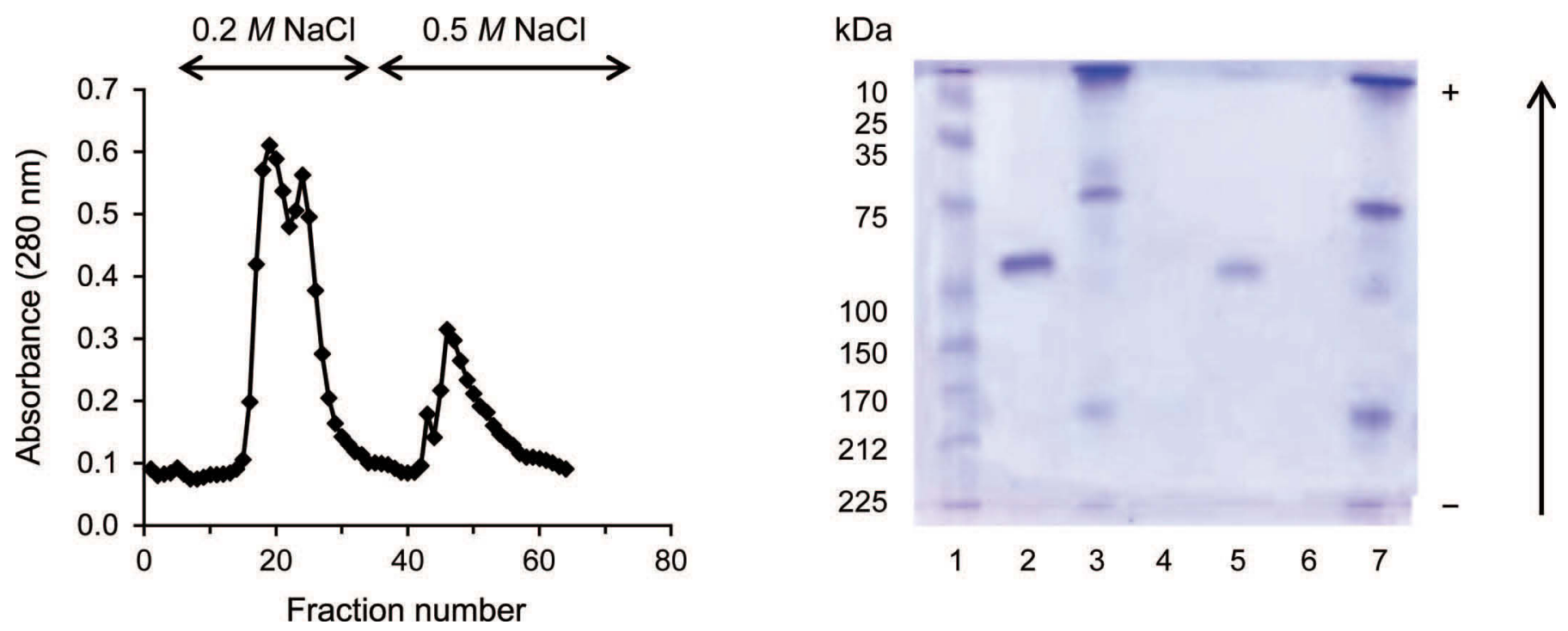

Figure 1. (A) Chromatography profile of lactoferrin isolation from ovine whey by CM-Sephadex, showing the elution of the retained proteins to the gel. (B) SDS-PAGE in 7.5\% polyacrylamide gel of the fractions obtained in the chromatography. 1: Molecular weight standards; 2: ovine lactoferrin; 3: excluded fraction; 4: fraction number 25; 5: fraction number 45; 6: fraction number 64; 7: ovine whey. Color version available online.

munochemical technique in 3 media: milk, whey, and phosphate buffer. Immunochemical techniques are appropriate when studying protein denaturation to determine the changes produced within its structure after being subjected to heat treatment, considering that denaturation usually diminish the recognition of conformational epitopes by antibodies (Tremblay et al., 2003). As shown in Figures 2a to 2f, lactoferrin concentration decreased with temperature and time of treatment in all the media studied. The $\mathrm{D}$ values obtained from those graphs and $\mathrm{Z}$ values that were obtained from the graph shown in Figure 3 are presented in Table 1. The graphs shown in Figure 2 correspond to individual experiments, whereas the $\mathrm{D}$ and $\mathrm{Z}$ values of Table 1 are the means of the values obtained from at least 2 independent experiments in which samples were analyzed in duplicate. We found that lactoferrin denatured more rapidly when it was heat treated in whey than in milk or phosphate buffer. The $\mathrm{D}$ value was 1.5 -fold higher in whey than in milk at $66^{\circ} \mathrm{C}$, around 4 times higher at $69^{\circ} \mathrm{C}$ and $72^{\circ} \mathrm{C}$, and 2.8 times higher at $75^{\circ} \mathrm{C}$. The $\mathrm{D}$ values obtained for lactoferrin heated in milk and phosphate buffer are more similar between them; they are approximately 1.2 times higher in milk treated at 66,69 , and $72^{\circ} \mathrm{C}$ and slightly lower in milk than in phosphate buffer at $75^{\circ} \mathrm{C}$. It is likely that the different composition between buffer and milk did not have so great an influence on lactoferrin thermoresistance at $75^{\circ} \mathrm{C}$ because that temperature causes a higher degree of denaturation. The denaturation process of lactoferrin has shown a very high dependence on temperature when it is subjected to treatment in whey, because the $\mathrm{Z}$ value obtained in this medium, $8.1^{\circ} \mathrm{C}$, was lower than those obtained in phosphate buffer and milk, at 12.1 and $10.2^{\circ} \mathrm{C}$, respectively.

The comparison of $\mathrm{D}$ values obtained for the immunoreactivity decrease of ovine lactoferrin with those reported by our group for bovine lactoferrin, also measuring the loss of immunoreactivity to estimate denaturation (Sánchez et al., 1992b), shows some differences between them. If we compare the results obtained at the temperature coincident in both studies, which is $72^{\circ} \mathrm{C}$, we observe that the $\mathrm{D}$ value is 4 times higher for bovine lactoferrin than for ovine lactoferrin when treated in phosphate buffer and 1.5 times lower when treated in milk. The $\mathrm{Z}$ values obtained for bovine lactoferrin were $17^{\circ} \mathrm{C}$ for the form devoid of iron both in milk and phosphate buffer, higher than those obtained for ovine lactoferrin, which were 10 and $12^{\circ} \mathrm{C}$, respectively, which could indicate that the denaturation of the bovine protein is less dependent on temperature. However, it is necessary to take into account that in the study by Sánchez et al. (1992b) the temperature range used to determine the $\mathrm{Z}$ value for bovine lactoferrin denaturation was between 72 and $85^{\circ} \mathrm{C}$ and for ovine lactoferrin between 66 and $75^{\circ} \mathrm{C}$, this can change the $\mathrm{Z}$ values considerably. The only study that has been published on thermoresistance of sheep lactoferrin was performed by our group in collaboration with another research group (Conesa et al., 2008). Those studies were done by calorimetry and the thermogram obtained for the native lactoferrin presented a main peak with a 

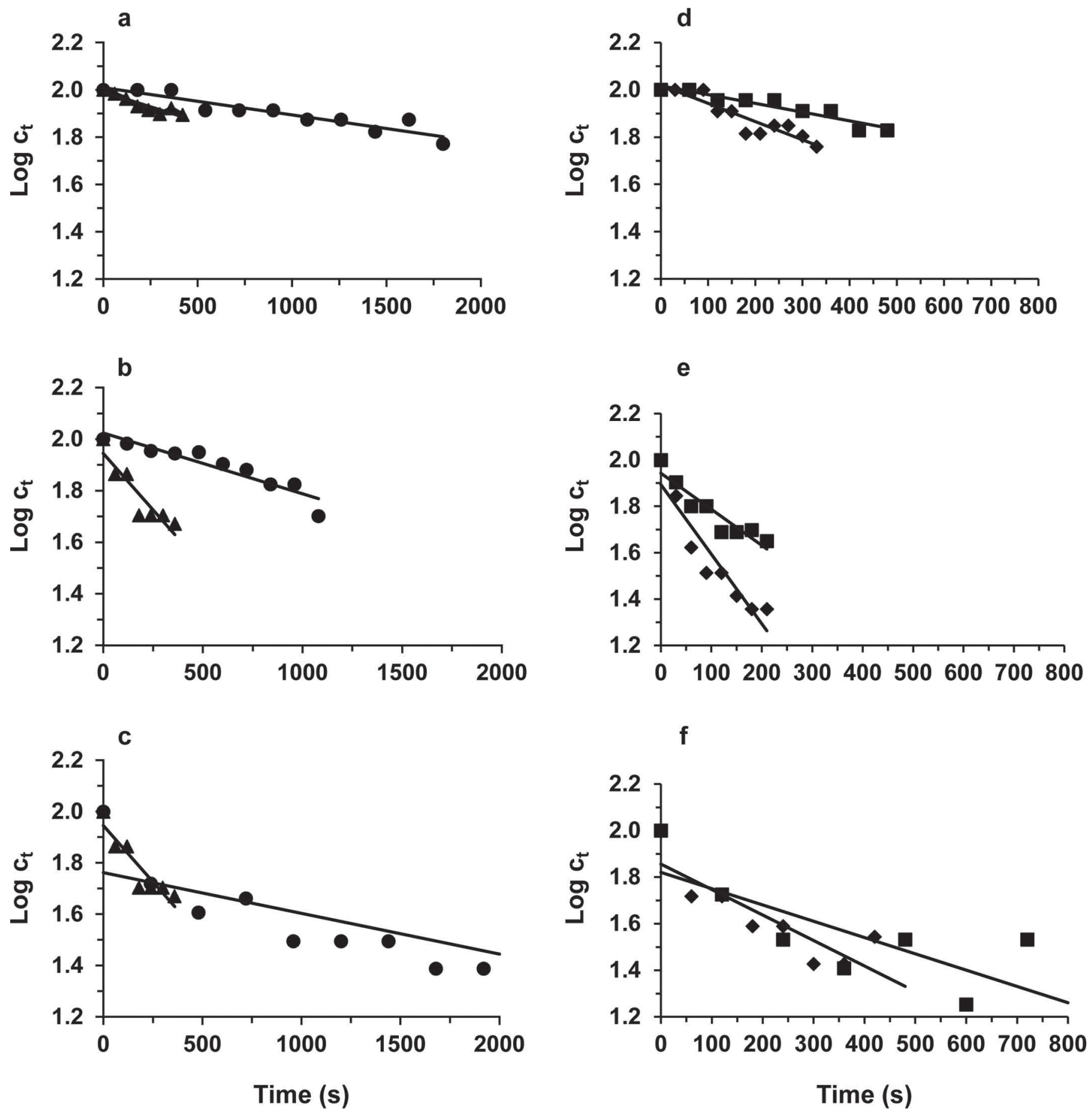

Figure 2. Effect of heat treatment on the denaturation of ovine lactoferrin treated in milk (a, d), whey (b, e), and phosphate buffer (c, f) at different temperatures: $\left(66^{\circ} \mathrm{C}, \boldsymbol{\Delta} 69^{\circ} \mathrm{C},-72^{\circ} \mathrm{C}, 75^{\circ} \mathrm{C}\right)$; $\mathrm{c}_{\mathrm{t}}$ is the concentration of immunoreactive protein at each holding time expressed as a percentage of the initial concentration. Lines represent linear regression.

maximum temperature of denaturation of $70.2^{\circ} \mathrm{C}$ and for the iron-saturated lactoferrin of $89.5^{\circ} \mathrm{C}$. When these values are compared with those we previously obtained also by calorimetry for bovine lactoferrin devoid of iron (Sánchez et al., 1992b), we found values for the maximum temperature of denaturation of $60^{\circ} \mathrm{C}$ and for the iron-saturated form of $86^{\circ} \mathrm{C}$, in both cases lower than those reported for ovine lactoferrin. However, it has to be taken into account that the parameters measured by calorimetry correspond to the whole process 
Table 1. D- and Z-values for the process of ovine lactoferrin denaturation in milk, whey, and phosphate buffer determined by its loss of immunoreactivity ${ }^{1}$

\begin{tabular}{lccc}
\hline Value $^{2}$ & Milk & Whey & $\begin{array}{c}\text { Phosphate } \\
\text { buffer }\end{array}$ \\
\hline $\mathrm{D}_{66}(\mathrm{~s})$ & 6,367 & 4,290 & 5,031 \\
$\mathrm{D}_{69}(\mathrm{~s})$ & 4,234 & 956 & 3,688 \\
$\mathrm{D}_{72}(\mathrm{~s})$ & 1,970 & 481 & 1,639 \\
$\mathrm{D}_{75}(\mathrm{~s})$ & 860 & 311 & 984 \\
$\mathrm{Z}\left({ }^{\circ} \mathrm{C}\right)$ & 10.2 & 8.1 & 12.1 \\
\hline${ }^{1} \mathrm{D}=$ decimal reduction times; $\mathrm{Z}=$ temperature change required for \\
1-log change in D-value.
\end{tabular}

of denaturation, whereas by measuring the loss of immunoreactivity we only consider the initial phase of the denaturation process.

The results obtained in the present study indicate a different thermoresistance of bovine and ovine lactoferrins depending on the medium of treatment. Although some studies that compare the structure of both proteins indicate that they are very similar with more than $80 \%$ homology (Buchta, 1991), some differences are reported in the proportion of secondary structures, which could explain their different thermoresistance (Shimazaki et al., 1991). It is well known that the iron bound to lactoferrin increases its thermoresistance, as the saturated molecules present a more compact conformation (Sánchez et al., 1992b; Castillo et al., 2012). Therefore, and taking into account that the iron saturation of ovine lactoferrin analyzed in this study was $19 \%$, a higher resistance would be expected of this native protein than that of apo bovine lactoferrin. Bovine lactoferrin is more heat resistant in phosphate buffer, whereas ovine lactoferrin is more resistant in milk. These differences could be explained by the different composition of sheep milk compared with bovine milk, especially for its high content of caseins (Park et al., 2007) that have a high buffering capacity (Ma and Barbano, 2003).

The concentration of immunoreactive ovine lactoferrin obtained for each temperature and holding time was

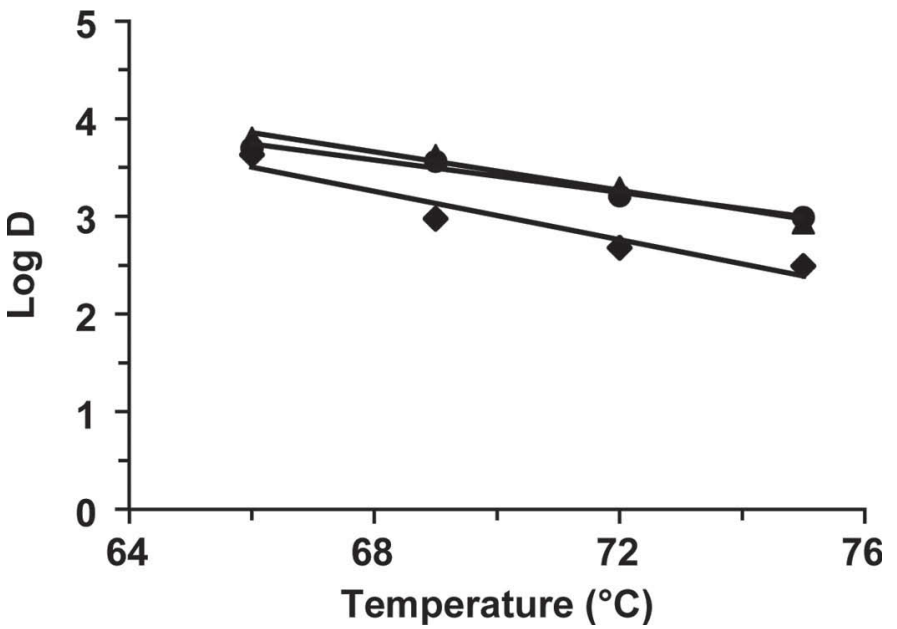

Figure 3. Variation of D (decimal reduction time) values with temperature for the process of denaturation of ovine lactoferrin treated in milk ( $\mathbf{\Delta})$, whey $(\bullet)$, and phosphate buffer $(\bullet)$. Lines represent linear regression.

analyzed as described in the Materials and Methods section to determine the rate constants for lactoferrin denaturation in the 3 media used for heat treatment. According to the least square criterion of the Solver function using the Excel 5.0 program, the mean value was estimated from the reaction order values obtained in the 3 treatment media at all the temperatures studied, and it was $\mathrm{n}=1.5$ obtaining $\mathrm{k}$ values shown in Table 2. The values for the correlation coefficients $\left(\mathrm{r}^{2}\right)$ obtained were in the range of 0.66 to 0.92 , and those for the mean square error were between 0.06 and 0.13 . The correlation between the immunoreactive values of lactoferrin concentrations experimentally determined and those obtained using the equation for lactoferrin heat treated in milk, whey, and buffer at all temperatures and holding times are shown in Figure 4a to 4c, showing a very good correlation coefficient.

The order of reaction of 1.5 is coincident with values obtained for denaturation of other bovine whey proteins such as $\alpha$-lactalbumin (Wehbi et al., 2005), IgG, IgA, and IgM (Mainer et al., 1997), and lactoperoxidase

Table 2. Thermodynamic parameters for denaturation of ovine lactoferrin determined by the loss of immunoreactivity in milk, whey, and phosphate buffer assuming a reaction order of $n=1.5^{1}$

\begin{tabular}{|c|c|c|c|c|c|c|c|c|c|c|c|c|}
\hline $\begin{array}{l}\text { Temperature } \\
\left({ }^{\circ} \mathrm{C}\right)\end{array}$ & \multicolumn{4}{|c|}{ Milk } & \multicolumn{4}{|c|}{ Whey } & \multicolumn{4}{|c|}{ Phosphate buffer } \\
\hline 66 & 2.75 & 7.21 & 0.90 & 0.06 & 3.73 & 9.41 & 0.66 & 0.10 & 4.51 & 11.57 & 0.767 & 0.13 \\
\hline 72 & 7.68 & 19.96 & 0.86 & 0.07 & 58.37 & 139.98 & 0.92 & 0.09 & 14.44 & 31.59 & 0.911 & 0.08 \\
\hline 75 & 17.57 & 45.98 & 0.85 & 0.09 & 162.75 & 390.92 & 0.92 & 0.07 & 24.15 & 67.13 & 0.834 & 0.11 \\
\hline
\end{tabular}



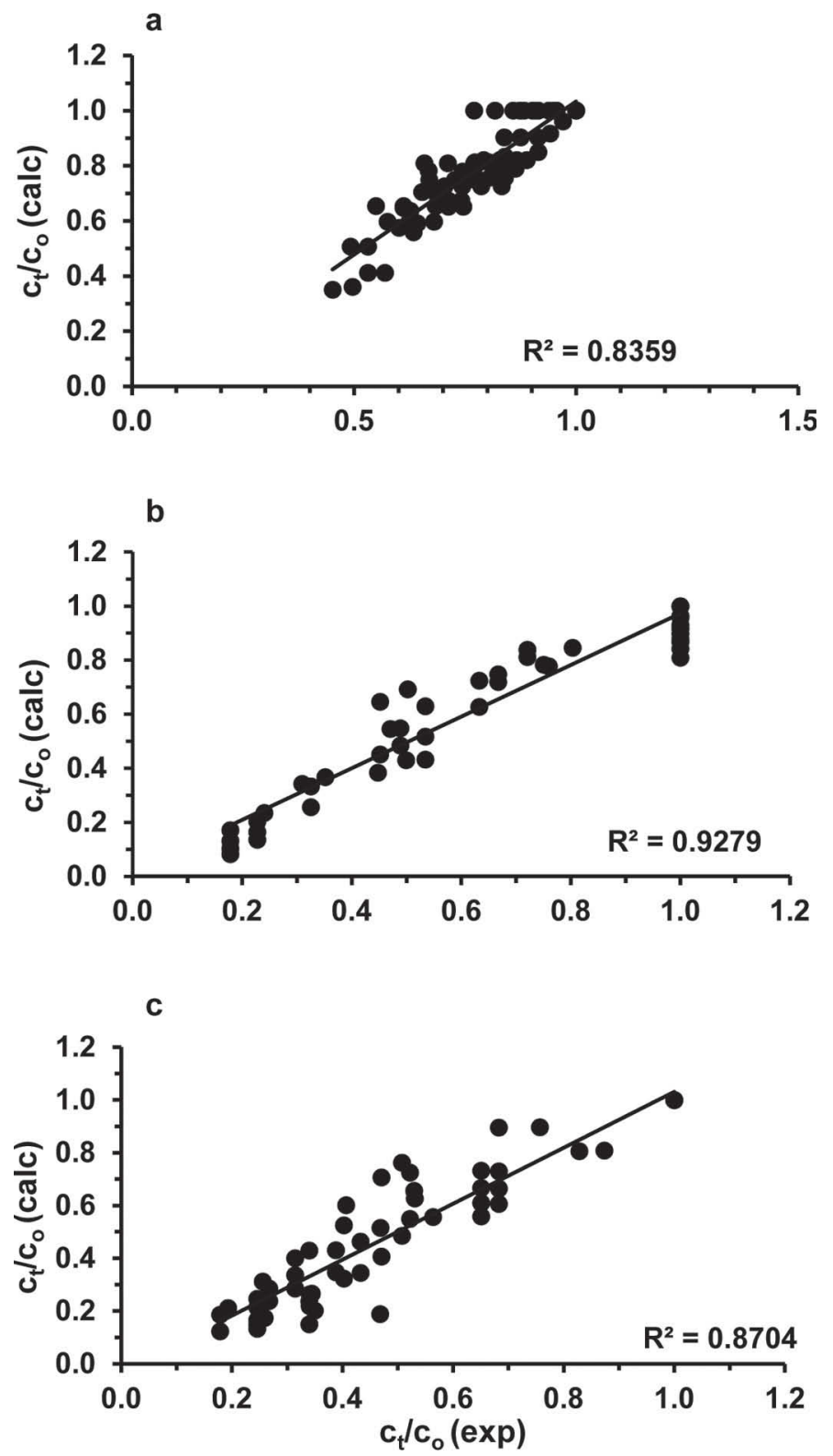

Figure 4. Correlation between the experimental values of concentration (exp) and those calculated (calc) for lactoferrin treated in milk (a), whey (b), and phosphate buffer (c) assuming an order of reaction $\mathrm{n}=1.5$. The concentration of lactoferrin is expressed as the ratio ct/ $\mathrm{co}$, where $\mathrm{co}=$ initial concentration of protein and ct $=$ the concentration at each time of heat treatment. Lines represent linear regression.

(Marín et al., 2003), and also for human recombinant lactoferrin from rice (Castillo et al., 2012). However, the order of reaction obtained for ovine lactoferrin is higher than that obtained for bovine lactoferrin that was of 1 (Sánchez et al., 1992b), which could indicate that denaturation of ovine lactoferrin and of human recombinant is more dependent on its concentration than that of bovine origin. The rate constants for ovine lactoferrin denaturation are higher in whey than in phosphate buffer, and in this medium higher than in milk, which corroborates the influence of treatment medium on its thermoresistance.

The variation of rate constants with temperature in the 3 media studied represented in Figure 5 allows obtaining the activation energy values shown in Table 3. The high value found for activation energy obtained for lactoferrin in whey, of $389.84 \mathrm{~kJ} / \mathrm{mol}$, compared with that obtained in milk and buffer, of 194.09 and 178.58 $\mathrm{kJ} / \mathrm{mol}$, respectively, indicates that lactoferrin interacts with whey proteins, possibly more strongly than with proteins in milk. It has been previously reported the interaction of bovine lactoferrin with other whey proteins, such as $\beta$-lactoglobulin and $\operatorname{IgA}$ (Lampreave et al., 1990), could favor the denaturation process of lactoferrin or the formation of aggregates between molecules of lactoferrin and of these with other whey proteins, by establishing noncovalent bounds or mediated by interchange reactions between disulfide bridges. It has been reported that the apo and native forms of bovine lactoferrin are more susceptible to aggregate during heat treatment than the iron-saturated form, taking into account the less compact structure of the apo form (Brisson et al., 2007a). Likewise, another study by Brisson et al. (2007b) reported that heat treatment of $70^{\circ} \mathrm{C}$ produced the formation of complexes between lactoferrin and some milk proteins such as $\beta$-lactoglobulin, $\alpha$-lactalbumin, $\alpha_{\mathrm{S} 2^{-}}$casein, and $\kappa$-casein, through interchange between disulfide bridges. The results of our study indicate that, when ovine lactoferrin is subjected to heat treatment, its interaction with whey proteins is higher if casein is not present; therefore, it loses its immunoreactivity earlier in whey than in milk.

The values of the activation energy for the denaturation process of lactoferrin permitted to determine the thermodynamic parameters for its process of de-

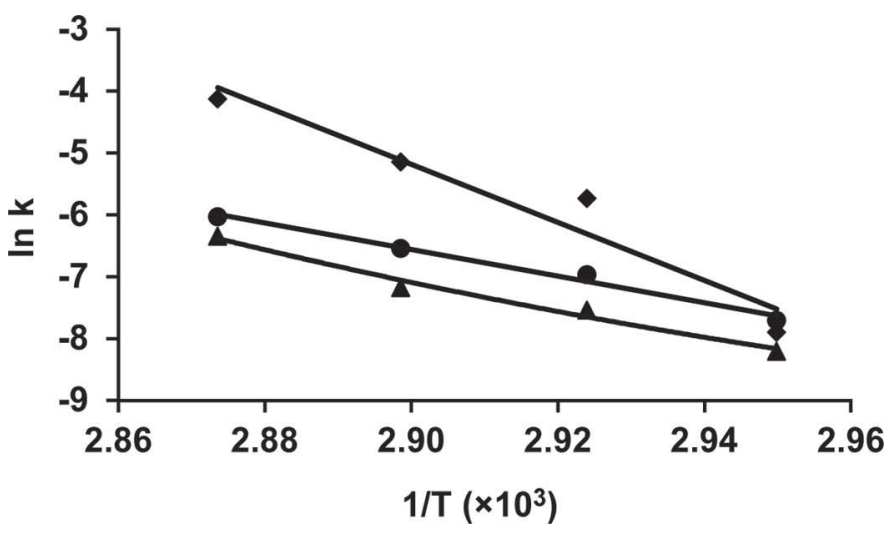

Figure 5. Variation of rate constant (k), with the reciprocal of absolute temperature $(1 / \mathrm{T})$ for the denaturation of ovine lactoferrin in milk ( $)$, whey $(\bullet)$, and phosphate buffer $(\bullet)$ for a reaction order of $\mathrm{n}=1.5$. Lines represent linear regression. 
Table 3. Thermodynamic parameters for denaturation of ovine lactoferrin assuming a reaction order $\mathrm{n}=1.5^{1}$

\begin{tabular}{|c|c|c|c|c|c|c|c|c|c|}
\hline \multirow[b]{2}{*}{ Temperature } & \multicolumn{3}{|c|}{$\begin{array}{c}\text { Milk } \\
\mathrm{E}_{\mathrm{A}}=194.09 \mathrm{~kJ} / \mathrm{mol}\end{array}$} & \multicolumn{3}{|c|}{$\begin{array}{c}\text { Whey } \\
\mathrm{E}_{\mathrm{A}}=389.84 \mathrm{~kJ} / \mathrm{mol}\end{array}$} & \multicolumn{3}{|c|}{$\begin{array}{c}\text { Phosphate buffer } \\
\mathrm{E}_{\mathrm{A}}=178.59 \mathrm{~kJ} / \mathrm{mol}\end{array}$} \\
\hline & $\Delta \mathrm{H} \#$ & $\Delta \mathrm{S} \#$ & $\Delta \mathrm{G} \#$ & $\Delta \mathrm{H} \#$ & $\Delta \mathrm{S} \#$ & $\Delta \mathrm{G} \#$ & $\Delta \mathrm{H} \#$ & $\Delta \mathrm{S} \#$ & $\Delta \mathrm{G} \#$ \\
\hline $69^{\circ} \mathrm{C}$ & 191.26 & 0.2583 & 102.93 & 387.00 & 0.8415 & 99.21 & 175.73 & 0.2172 & 100.99 \\
\hline $72^{\circ} \mathrm{C}$ & 191.23 & 0.2582 & 102.15 & 386.98 & 0.8414 & 96.68 & 175.71 & 0.2172 & 100.56 \\
\hline $75^{\circ} \mathrm{C}$ & 191.21 & 0.2581 & 101.38 & 386.95 & 0.8414 & 94.16 & 175.69 & 0.2172 & 100.12 \\
\hline
\end{tabular}

${ }^{1}$ The parameters determined are the activation energy $\left(\mathrm{E}_{\mathrm{A}}\right)$, the variation of activation enthalpy $\Delta \mathrm{H} \#(\mathrm{~kJ} / \mathrm{mol})$, the variation of activation entropy $\Delta \mathrm{S} \#(\mathrm{~kJ} / \mathrm{mol} \cdot \mathrm{K})$, and the variation of the free energy of activation $\Delta \mathrm{G} \#(\mathrm{~kJ} / \mathrm{mol})$.
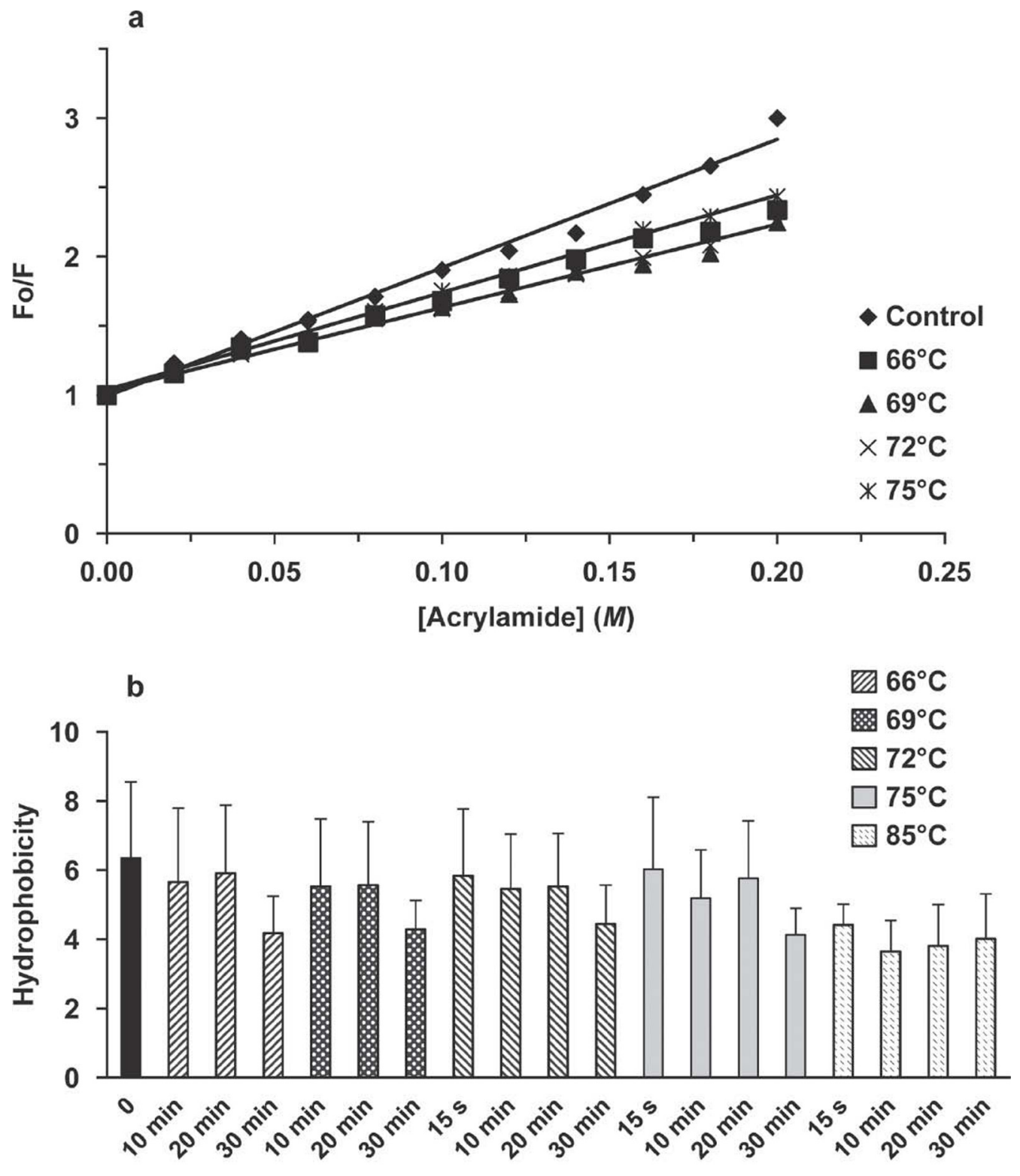

Heat treatment

Figure 6. (a) Stern-Volmer graph for determination of ovine lactoferrin hydrophobicity subjected to several heat treatments for 20 min. $\mathrm{F}_{0}$ = initial fluorescence of ovine lactoferrin without acrylamide. $\mathrm{F}=$ fluorescence of ovine lactoferrin with increasing concentrations of acrylamide. Lines represent linear regression. (b) Effect of several heat treatments on ovine lactoferrin hydrophobicity in phosphate buffer. The results are the mean \pm standard deviation of values from 4 independent experiments. 
naturation that are shown in Table 3 . The variations of activation enthalpy and of activation entropy are very similar at the 4 temperatures studied within the same treatment media. However, some differences are observed in the values of variation of the activation enthalpy among the treatment media, being approximately 2-fold higher when the protein is treated in whey compared with values obtained in milk and phosphate buffer. The variation of activation entropy obtained is also higher for the treatment of lactoferrin in whey compared with milk or phosphate buffer. The positive values obtained for the variation of activation entropy in all cases would suggest that lactoferrin undergoes a conformational change in the 3 media used for heat treatment that predominates over aggregation processes.

The changes in the hydrophobicity of lactoferrin after heat treatments at different temperatures and holding times were determined by fluorescence measurement using acrylamide. The values of apparent hydrophobicity constants were calculated from the graphs shown in Figure 6a. The values of apparent hydrophobicity constants for the heat treatments at the 4 temperatures studied are represented in Figure 6b. As it can be observed, nontreated lactoferrin showed the highest constant, and with the increase of temperature the constant decreased. This decrease is very small for the treatments of $66,69,72$, and $75^{\circ} \mathrm{C}$ at all holding times except at those maintained for $30 \mathrm{~min}$, with the values obtained at the different temperatures being very similar. In the samples treated at $85^{\circ} \mathrm{C}$, the hydrophobicity constant was markedly lower at all the holding times, the values being very similar among them and also similar to those obtained for the other temperatures maintained $30 \mathrm{~min}$. The decrease in the hydrophobicity constant that is observed when lactoferrin is heat treated indicates a change in its conformation, giving a more hydrophobic atmosphere that makes the tryptophan residues less accessible (Sreedhara et al., 2010). Some studies explain the decrease in the hydrophobicity of a protein by its aggregation, which hide the tryptophan residues and could compensate for the effect of a greater exposition of tryptophan due to lactoferrin unfolding (Kulmyrzaev et al., 2005). However, these aggregation phenomena have not been deduced from the kinetic data obtained in the present study by measuring the loss of immunoreactivity.

The results obtained in this study allow us to conclude that is essential to take into account the relevance of treatment media to predict the thermoresistance of ovine lactoferrin and that high pasteurization treatments (HTST, $72^{\circ} \mathrm{C}$ for $15 \mathrm{~s}$ ) do not produce loss of immunoreactivity of ovine lactoferrin and, consequently, major changes of its structure. Therefore, that treat- ment would allow maintaining the activity of lactoferrin in whey and it could also be appropriate for the treatment of functional products supplemented with ovine lactoferrin.

\section{ACKNOWLEDGMENTS}

We acknowledge the Universidad de Los Andes Mérida (Venezuela), Universidad de Zaragoza (Spain), AECID (Agencia Española de Cooperación Internacional para el Desarrollo, Madrid, Spain), Gobierno de Aragón (Spain), and the European Social Fund. This work was supported by a CICYT (Comisión Interministerial de Ciencia y Tecnología, Madrid, Spain) grant (AGL2010-20835).

\section{REFERENCES}

Anema, S. G. 2009. The whey proteins in milk: Thermal denaturation, physical interactions and effects on the functional properties of milk. Pages 239-273 in Milk Proteins. Food Science and Technology. H. Singh, and T. Abby, ed. Academic Press, New York, NY.

Brisson, G., M. Britten, and Y. Pouliot. 2007a. Heat-induced aggregation of bovine lactoferrin at neutral $\mathrm{pH}$ : Effect of iron saturation. Int. Dairy J. 17:617-624.

Brisson, G., M. Britten, and Y. Pouliot. 2007b. Effect of iron saturation on the recovery of lactoferrin in rennet whey coming from heat-treated skim milk. J. Dairy Sci. 90:2655-2664.

Buchta, R. 1991. Ovine lactoferrin: Isolation from colostrums and characterization. J. Dairy Res. 58:211-218.

Castillo, E., M. D. Pérez, I. Franco, M. Calvo, and L. Sánchez. 2012. Kinetic and thermodynamic parameters for heat denaturation of human recombinant lactoferrin from rice. Biochem. Cell Biol. 90:389-396.

Conesa, C., L. Sánchez, M. D. Pérez, and M. Calvo. 2007. A calorimetric study of thermal denaturation of recombinant human lactoferrin from rice. J. Agric. Food Chem. 55:4848-4853.

Conesa, C., L. Sánchez, C. Rota, M. D. Pérez, M. Calvo, S. Farnaud, and R. W. Evans. 2008. Isolation of lactoferrin from milk of different species: Calorimetric and antimicrobial studies. Comp. Biochem Physiol. B Biochem. Mol. Biol. 150:131-139.

Considine, T., H. A. Patel, S. G. Anema, H. Singh, and L. K. Creamer. 2007. Interactions of milk proteins during heat and high hydrostatic pressure treatments. Innov. Food Sci. Emerg. Technol. 8:1-23.

Eftink, M. R., and C. A. Ghiron. 1981. Fluorescence quenching studies with proteins. Anal. Biochem. 114:199-227.

Kulmyrzaev, A., D. Levieux, and E. Dufour. 2005. Front-face fluorescence spectroscopy allows the characterization of mild heat treatment applied to milk. Relations with the denaturation of milk proteins. J. Agric. Food Chem. 53:502-507.

Lampreave, F., A. Piñeiro, J. H. Brock, H. Castillo, L. Sánchez, and M. Calvo. 1990. Interaction of bovine proteins with other proteins of milk whey. Int. J. Biol. Macromol. 12:2-5.

Ma, Y., and D. M. Barbano. 2003. Serum protein and casein concentration: Effect on $\mathrm{pH}$ and freezing point of milk with added $\mathrm{CO}_{2}$. J. Dairy Sci. 86:1590-1600.

Mainer, G., L. Sánchez, J. M. Ena, and M. Calvo. 1997. Kinetic and thermodynamic parameters for heat denaturation of bovine milk IgG, IgA and IgM. J. Food Sci. 62:1034-1038.

Marín, E., L. Sánchez, M. D. Pérez, P. Puyol, and M. Calvo. 2003. Effect of heat treatment on bovine lactoperoxidase activity in skim milk: Kinetic and thermodynamic analysis. J. Food Sci. 68:89-93.

Mata, L., L. Sánchez, D. R. Headon, and M. Calvo. 1998. Thermal denaturation of human lactoferrin and its effect on the ability to bind iron. J. Agric. Food Chem. 46:3964-3970. 
Mayayo, C., M. Montserrat, S. J. Ramos, M. J. Martínez-Lorenzo, M. Calvo, L. Sánchez, and M. D. Pérez. 2014. Kinetic parameters for high-pressure-induced denaturation of lactoferrin in human milk. Int. Dairy J. 39:246-252.

Park, Y. W., M. Juárez, M. Ramos, and G. F. W. Haenlein. 2007. Physico-chemical characteristics of goat and sheep milk. Small Rumin. Res. 68:88-113.

Sánchez, L., M. Calvo, and J. H. Brock. 1992a. Biological role of lactoferrin. Arch. Dis. Child. 67:657-661.

Sánchez, L., J. M. Peiró, H. Castillo, M. D. Pérez, J. M. Ena, and M. Calvo. 1992b. Kinetic parameters for denaturation of bovine milk lactoferrin. J. Food Sci. 57:873-879.

Shimazaki, K., N. Kawano, and Y. C. Yoon. 1991. Comparison of bovine sheep and goat milk lactoferrins in their electrophoretic behavior conformation, immunochemical properties and lectin reactivity. Comp. Biochem. Physiol. B 98:417-422.
Sreedhara, A., F. Ragnar, V. Prakash, D. Krowarsch, T. Langsrud, P. Kaul, T. Devold, and G. Vegarud. 2010. A comparison of effects of $\mathrm{pH}$ on the thermal stability and conformation of caprine and bovine lactoferrin. J. Dairy Sci. 20:487-494.

Tremblay, L., M. Laporte, L. F. Jeonil, D. Dupont, and P. Raquin. 2003. Quantitation of proteins in milk and milk products. Pages 49-138 in Advanced Dairy Chemistry. P. F. Fox, and L. H. McSweeney, ed. Vol. 1: Proteins. Kluwer Academic, New York, NY.

Wehbi, Z., M. D. Pérez, L. Sánchez, C. Pocovi, C. Barbana, and M. Calvo. 2005. Effect of heat treatment on denaturation of bovine alpha-lactalbumin: Determination of kinetic and thermodynamic parameters. J. Agric. Food Chem. 53:9730-9736.

Yoshida, S., and Ye-Xiuyun. 1991. Isolation of lactoperoxidase and lactoferrins from bovine milk acid whey by carboxymethyl cation exchange chromatography. J. Dairy Sci. 74:1439-1444. 